\title{
Average solar UV radiation dosimetry in central Nigeria
}

\author{
Igbawua Tertsea $^{1, *}$, Ikyo Barnabas ${ }^{2}$, Agba Emmanuel $^{3}$ \\ ${ }^{1}$ Faculty of Science, Federal University of Agriculture, Makurdi, Benue State, Nigeria \\ ${ }^{2}$ Department of Physics, Benue State University Makurdi and University of Surrey, Guildford, UK \\ ${ }^{3}$ Faculty of Science, University of Mkar, Mkar, Benue State, Nigeria \\ Email address: \\ talk2tertsee@yahoo.com (Igbawua T.)
}

\section{To cite this article:}

Igbawua Tertsea, Ikyo Barnabas, Agba Emmanuel. Average Solar UV Radiation Dosimetry in Central Nigeria. International Journal of Environmental Monitoring and Analysis. Vol. 1, No. 6, 2013, pp. 323-327. doi: 10.11648/j.ijema.20130106.18

\begin{abstract}
The measurement of solar UV radiation at a typical market setting (Gboko, Central Market, Benue State Nigeria) was done using a broadband UV meter and Polymer Polysulphone Dosimeters. The dosimeters were fitted on strategic solar radiation access areas on a plastic human figure and placed in the sun from 9:30am- 4:00pm. The dosimeter fitted on the fore head recorded the highest reading of $595 \mathrm{~J} / \mathrm{m}^{2}$ whereas the one positioned in the pocket (beneath the cloth) gave the least reading $2.7 \mathrm{~J} / \mathrm{m}^{2}$. The dosimeter placed in the Shade (Shop Canopy) also gave a low value of $45.4 \mathrm{~J} / \mathrm{m}^{2}$ and the mean UV radiation exposure was determined as $432 \pm 47 \mathrm{~J} / \mathrm{m}^{2}$. The work sets a reliable baseline data for solar UV radiation monitoring in central Nigeria. Appropriate recommendations have also been made to create awareness on the harmful effects of solar UV radiation.
\end{abstract}

Keywords: UV, Radiation, Dosimetry, Nigeria

\section{Introduction}

Market arenas, playgrounds, tourist sites, farmlands, work and construction sites in Nigeria are the places that present significant health risks to most people who expose their bodies in UV radiation without adequate protection. The risk is most significant in market sites, car parks and work sites located in the villages having little or no shade covers for UV protection. In Africa, there is predominance in the naturally brown or black skin type which is very much resistant to instant sunburn or other acute effects of over exposure to solar UV radiation $[1,2]$. This has made the general public to neglect the necessary UV protection measures resulting to increased risks associated with chronic effects of UV radiation exposure.

Solar UV radiation is responsible for the synthesis of vitamin D but excessive exposure to it causes sunburn, eye problems (such as cataracts, pterygium), skin aging, skin cancer and immune depression [1, 3-6]. Solar UV radiation also penetrates to ecological depths in aquatic systems and can affect both marine and freshwater systems from major biomass producers (phytoplankton) to consumers (zooplankton) in the food web [7]. The known immediate and acute effect of over exposure to Solar Ultraviolet Radiation (UVR) on skin is sunburn (erythemal). This occurs 12-14 hours after exposure if the dose of erythemal irradiance has exceeded 1 unit of Minimum Erythemal Dose (MED). MED depends on skin type and it has a range of 200 to $500 \mathrm{~J} / \mathrm{m}^{2}$ among the light skinned individuals [8, 9]. It has been shown that the efficiency of producing Erythermal increases by up to 5 orders of magnitude in the $280 \mathrm{~nm}$ to $350 \mathrm{~nm}$ wavelength range. The black skin type contains a dark biological pigment (Melanin), which absorbs harmful and visible radiation and thus prevents the skin from sunburn and other acute effects of solar UV radiation on the skin [1]. It has also been shown that UV-B suppresses the body immune response to Herpes simplex virus and to skin lesion development and may affect the spleen. The eyes are more vulnerable; UV-B causes cataract and snow blindness [10]. In agriculture, UV-B increases plant's susceptibility to diseases, hence it's over exposure poses a great threat in central Nigeria where farming is the main occupation.

Many researchers have done a lot of work in reporting the estimation of global and diffused solar radiation in various parts of Nigeria employing various methods and techniques. [11], estimated the solar radiation at Uturu (Abia State) (latitude $05.33^{\circ} \mathrm{N}$ and $06.03^{\circ} \mathrm{N}$ ) in October, 2007 using Hargreaves equation and the mean global solar $\mathrm{UV}$ radiation was reported as $1.89 \pm 0.82 \mathrm{kWh}$ [12] measured and reported that the average solar radiation that is received in Nigeria per day is as high as $20 \mathrm{MJ} / \mathrm{m}^{2}$. 
Nigeria is located in western Africa and has an approximate land mass of $910770 \mathrm{sq}$. $\mathrm{km}$ [13] with a population of more than 160 million. The country has six geopolitical regions and mainly based on geography. The north central is comprised of the middle belt region with relatively similar weather and geographic features (average sunshine, rainfall, ambient temperatures, humidity and wind speed) in general.

In this work, we have measured and estimated the solar UV radiation exposure $\left(\mathrm{J} / \mathrm{m}^{2}\right)$ on market traders and the general public that expose their bodies continuously for a long period of time in the solar UV radiation field. The measurement was carried out in a typical market setting in Gboko, Benue State of Central Nigeria. The research obtains reliable estimations of UVR for members of the general public in Central Nigeria. Also, it determines the cumulative erythemal dose $\left(\mathrm{J} / \mathrm{m}^{2}\right)$ received on different exposure parts of the body for a given exposure period which serves as a baseline for further research in this area and to regulators of environmental safety standards in Nigeria.

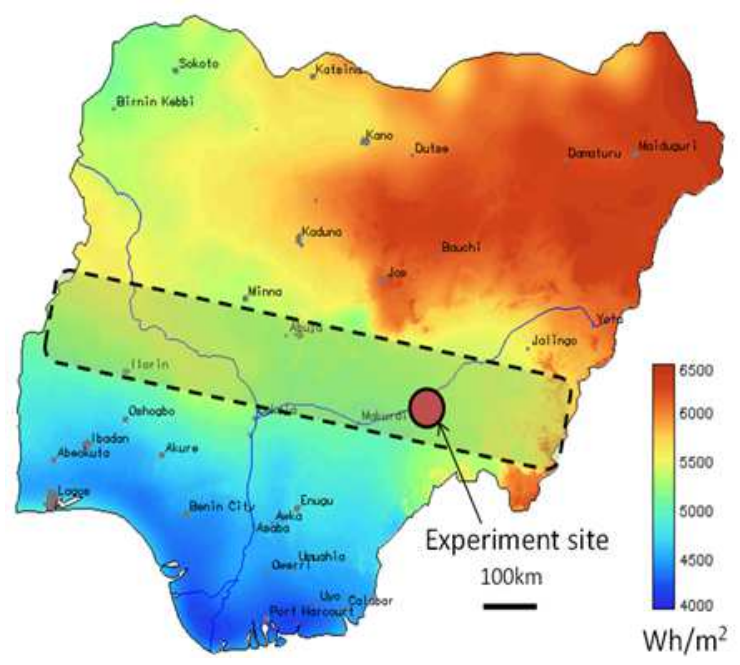

Figure 1. Yearly average of daily sums of global horizon irradiation in Nigeria. Dashed perimeter line indicates average coverage of central Nigeria [14].

\section{Materials and Methods}

\subsection{Study Site}

Measurements were taken at a typical market setting located in Gboko, Benue State, Nigeria with Latitude 07.19.416'N, Longitude 09.02.491'E and Elevation of $238 \mathrm{~m}$.

\subsection{Materials}

A digital UV broadband meter, the Educator (No. P3-6510), obtained from Ann Arbor (USA), was used for measuring UV exposures. The UV meter detects both UV-A and UV-B and then calculates the UV index and UV irradiance (solar power density in $\mathrm{mW} / \mathrm{m}^{2}$ ) through averaging the readings of the various wavelengths according to the Erythemal Action Spectrum.

The longitude, latitude and altitude of the measurement site were measured by a twelve-channel GPS (etrex by Garmin Ltd, USA). Fourteen pieces of polymer polysulphone dosimeter $(2 \mathrm{~cm} \times 2 \mathrm{~cm})$ were used in this work. Five dosimeters were used for calibration whereas the remaining nine dosimeters were attached on a plastic human dummy of $1.7 \mathrm{~m}$ tall dressed in light clothes. A UV/Vis spectrophotometer, (UV-Vis serial no. 6305, designed by Jenway Co. Ltd, UK) was used in measuring the change in dosimeter absorbance.

\subsection{Dosimeter Calibration and Experimental Model}

The calibration of the dosimeters was done at the measurement site on 7th March, 2012. It was done by subjecting five (5) dosimeters to series of solar UV radiation on a horizontal plane, while measuring the solar UV exposures with the UV meter. This was done to enable the dosimeters quantify UV exposures in $\mathrm{J} / \mathrm{m}^{2}$. The first dosimeter was exposed for $10 \mathrm{mins}$, the second $20 \mathrm{mins}$, third, fourth and fifth for a period of $30 \mathrm{mins}$, $40 \mathrm{mins}$, and $50 \mathrm{mins}$ respectively. The measurement time was taken between $12.00 \mathrm{pm}$ and $1.00 \mathrm{pm}$.

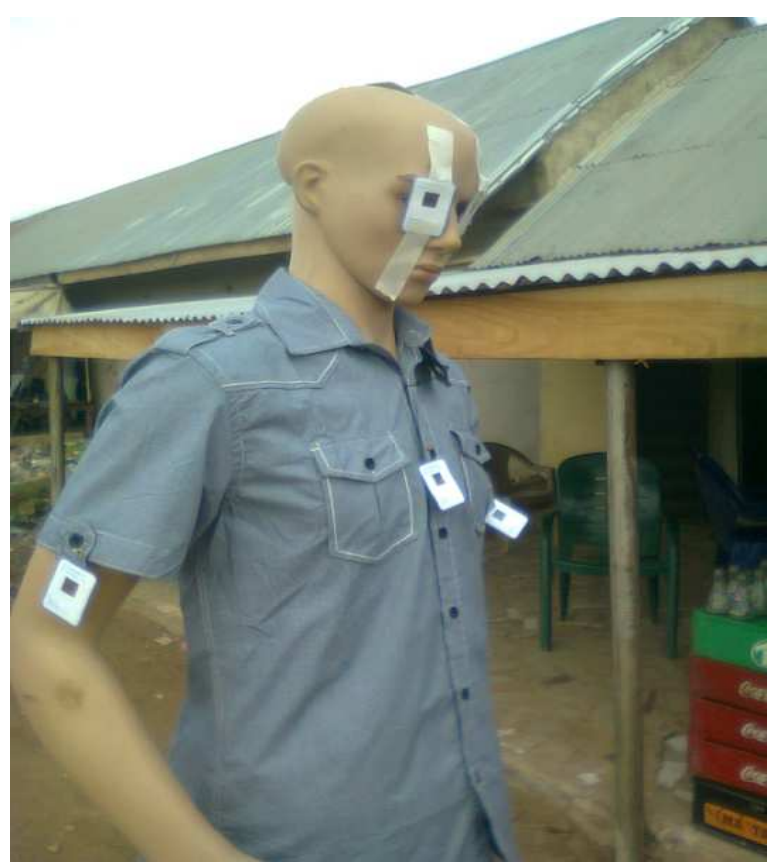

Figure 2. Dosimeters placed on plastic human figure to measure UV radiation

Specifically, the dosimeters are not manufactured and designed to measure absorbance. The main aim is to quantify cumulative UV radiation $\left(\mathrm{J} / \mathrm{m}^{2}\right)$, and hence the need for them to be calibrated so as to measure UV radiation.

Desired Quantity $\left(\mathrm{J} / \mathrm{m}^{2}\right)=$ Calibration factor (Constant) $\mathrm{x}$ Absorbance 
For linear calibration, the calibration factor is often taken as the gradient of a line and this may be sufficient approximation for a UV polysulphone dosimeter provided a linear range can be determined [8].

The UV exposure (E) of each individual dosimeter was calculated using equation (2) [8].

$$
E=\sum_{t_{1}}^{t_{2}} I \times \Delta t
$$

where $\mathrm{E}$ is the exposure in $\left(\mathrm{J} / \mathrm{m}^{2}\right)$, I is the measured irradiance $\left(\mathrm{W} / \mathrm{m}^{2}\right)$ and $\Delta \mathrm{t}$ is the exposure time interval from $\mathrm{t}_{1}$ to $\mathrm{t}_{2}$.

\subsection{UV Exposures}

Both calibration and plastic human dummy exposure were done at the same site and on the same day so as to avoid mismatch errors. Eight (8) dosimeters of size $2 \mathrm{~cm} \mathrm{x}$ $2 \mathrm{~cm}$ were tagged on different exposure parts of the plastic human figure (manikin) and placed under the sun from 9:30am to $4.00 \mathrm{pm}$ on 7th March, 2012 (Figure 2). One (1) dosimeter each was placed on the right eye, left eye, right hand, left hand, forehead, chest, back and the pocket. One dosimeter was tagged on another plastic manikin and placed in the shade on the same day and time. The polymer polysulphone undergoes UV induced photo degradation when exposed to UV wavelengths shorter than approximately 340nm [15]. The pre-exposure optical absorbance and post-exposure optical absorbance at 330nm $\left(\Delta \mathrm{A}_{330}\right)$ in a UV spectrophotometer (UV-Vis 6305 Jenway, UK) was measured and reported.

\section{Results}

Table 1 shows the results for cumulative exposure of the dosimeters during calibration. Equation (2) was used in calculating UV exposure of each dosimeter at an interval of ten (10) minutes. The total exposure for each dosimeter was the cumulative sum of the exposure calculated for the current exposure interval (10 minutes) and the sum of previous exposures of the dosimeters taken in that order. The UV exposure of each dosimeter was estimated from a single measurement made at the end of an interval of 10 minutes. The UV irradiance was therefore approximated to be constant for the 10-minute exposure intervals.

Table 1. Cumulative UV exposure of each dosimeter

\begin{tabular}{cccccc}
\hline S/no. & $\begin{array}{c}\text { Dosimeter } \\
\text { Exposure Time } \\
\text { (Minutes) }\end{array}$ & $\begin{array}{c}\text { Cumulative UV } \\
\text { exposure }\left(\mathbf{J} / \mathbf{m}^{2}\right)\end{array}$ & $\begin{array}{c}\text { Change in Optical exposure } \\
\text { Absorbance } \\
\left(\Delta A_{330}\right)\end{array}$ & $\begin{array}{c}\text { UV Irradiance for the } \\
\text { Exposure Interval } \\
\left(\mathbf{m W} / \mathbf{m}^{2} \cdot \mathbf{s}\right)\end{array}$ & $\begin{array}{c}\text { Approximate UV } \\
\text { exposure for each } \\
\text { Interval }\left(\mathbf{J} / \mathbf{m}^{2}\right)\end{array}$ \\
\hline 01 & 10.0 & 58.9 & 0.096 & 98.2 & 58.9 \\
02 & 20.0 & 109.1 & 0.136 & 83.7 & 50.2 \\
03 & 30.0 & 158.5 & 0.196 & 82.3 & 49.4 \\
04 & 40.0 & 207.9 & 0.226 & 82.8 & 49.7 \\
05 & 50.0 & 255.1 & 0.246 & 78.6 & 47.2 \\
\hline
\end{tabular}

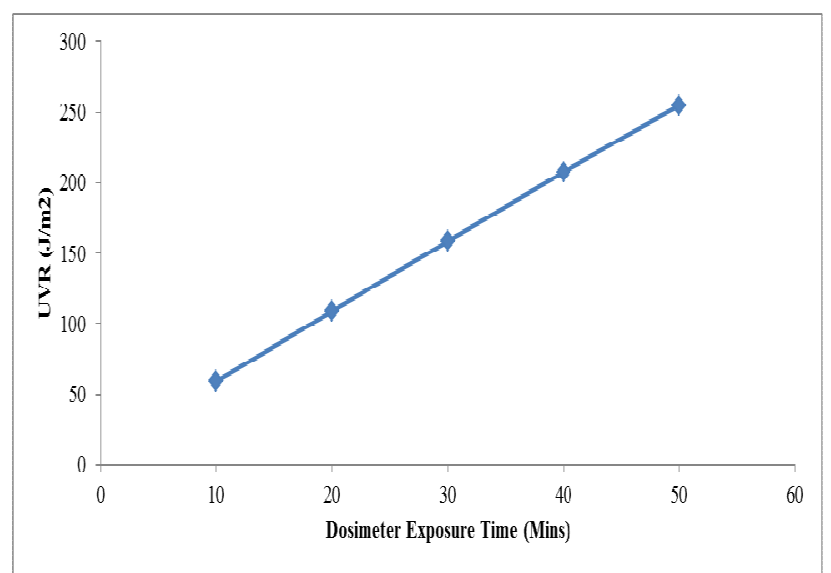

Figure.3. Dosimeter Calibration Curve

Figure 4 shows the calibration curve for cumulative UV exposure with dosimeter absorbance. The almost linear line indicates a strong relationship between increasing exposure to $\mathrm{UV}$ radiation and the absorbance in the measured exposure intervals of 10 minutes (between $12.00 \mathrm{pm}$ and $1.00 \mathrm{pm}$ ). Periods of cloud cover were avoided during the measurement so as to obtain better results. A straight line graph was therefore plotted to get the calibration equation which is $\mathrm{y}=907.6 \mathrm{x}$ with $\mathrm{R}^{2}=0.9006$. The calibration period was chosen around midday because of high intensities of UV exposures normally experienced around solar noon. If the calibration period were to exceed $1.00 \mathrm{pm}$ and run past $4.00 \mathrm{pm}$, the straight line graph (Figure 4) would have flatten and form a curve as only minimal exposures would be absorbed by the dosimeter as the time increases. Similarly, if the calibration proceeds until sun set, there would be no observable increase in UV exposure and absorbance with time. This is typical of UV polymer dosimeters curving away after excessive cumulative exposure to sunlight as a result of increasing limitation of the available polymer chains which increase the opacity of a dosimeter to a certain exposure limit [8]. 


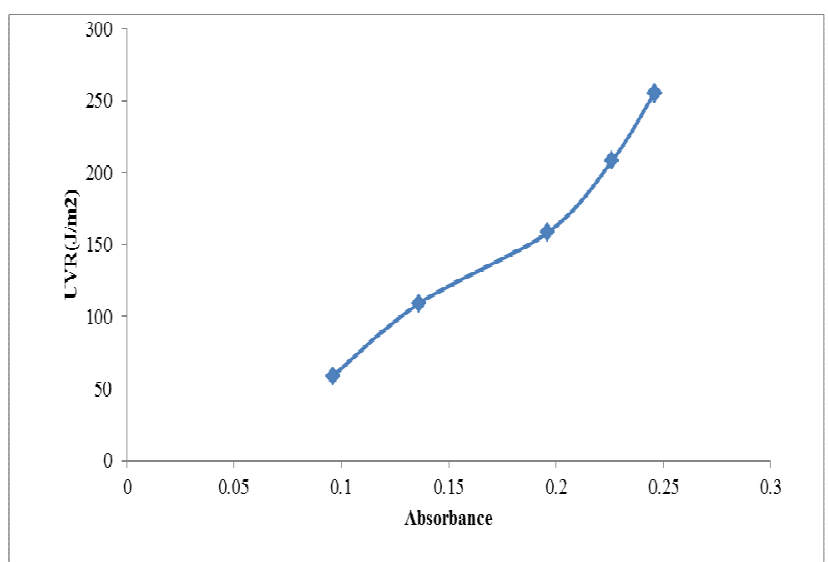

Figure 4. Polymer Polysulphone Dosimeter Response Curve

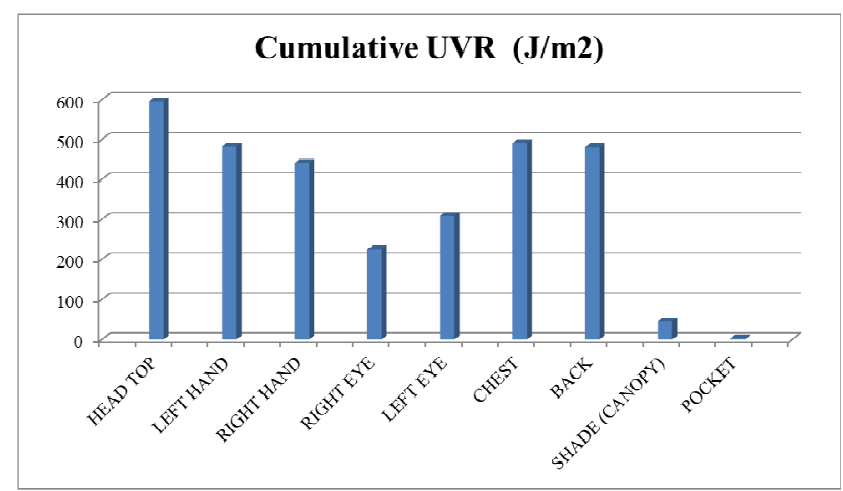

Figure 5. Cumulative Exposure of Dosimeters placed on various body sites

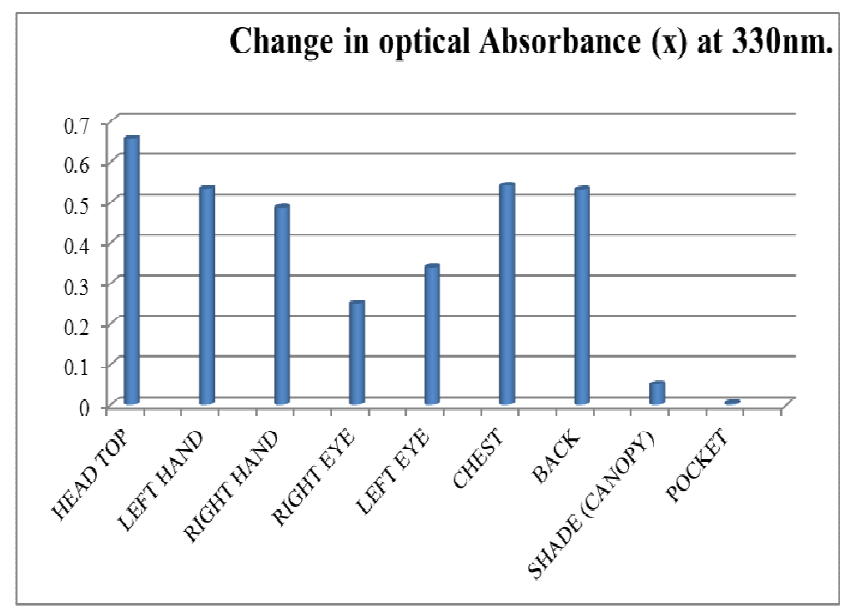

Figure 6. Change in optical Absorbance (x) at 330nm

\section{Discussion}

The polymer polysulphone dosimeter has been successfully calibrated with a calibration equation $\mathrm{y}=$ 907.6x $\left(\mathrm{R}^{2}=0.9006\right)$ to make the dosimeter effectively measure cumulative UV radiation in $\mathrm{J} / \mathrm{m}^{2}$. According to [9], calibrated measurements of personal UV exposures have been performed accurately over the past 30 years with the use of polysulphone and poly 2, 6-dimethyl-1, 4-phenylene oxide polymer dosimeters.
Different exposure parts of the body were also measured with the dosimeter and it was observed that, the dosimeter placed on the head (Top) recorded the highest cumulative UV radiation of $595.386 \mathrm{~J} / \mathrm{m}^{2}$, followed by the one placed on the chest with $491.012 \mathrm{~J} / \mathrm{m}^{2}$. The dosimeter placed in the pocket recorded the least cumulative UV radiation of 2.723 $\mathrm{J} / \mathrm{m}^{2}$ revealing that the clothing we put on everyday also assist in attenuating the solar UV radiation penetrating the skin thereby reducing the harm it would have caused on our bodies. Also, the dosimeter placed in the open shade (Canopy) recorded little cumulative UV radiation of 45.380 $\mathrm{J} / \mathrm{m}^{2}$. The dosimeters on the Left Hand and Right Hand both reported high UV exposures of 308.584 and 225.085 $\mathrm{J} / \mathrm{m}^{2}$ respectively. The small difference being attributed to the fact that the sun movement was not directed over head.

Studies by [16] reported similar UV exposures with polysulphone dosimeters. Calculated daily UV exposures in the shade during the winter ranged from 0.3 SED per day for top of head and 1.8 SED per day for chin while calculated UV exposures in shade during the summer ranged from 0.3 SED per day for top of head and 4.6 SED for chin [1 SED is equal to $100 \mathrm{~J} / \mathrm{m}^{2}$ [16]]. In this research, the dosimeter in the shop canopy gave a reading of 45.380 $\mathrm{J} / \mathrm{m}^{2}$, and it clearly shows that even the shade do not provide 100 per cent protection against UV radiation exposures as also shown by [16].

The Mean UV radiation exposure in this work was determined to be $432.147 \pm 47 \mathrm{~J} / \mathrm{m}^{2}$ for a 6.5 hour-exposure period. The mean UV radiation exposure is higher than the recommended value by International Commission on Non-Ionizing Radiation Protection (ICNIRP) for occupational exposure limit of $30 \mathrm{~J} / \mathrm{m}^{2}$ [17], for a 6.5 hourexposure period for both the eyes and skin. This is therefore capable of causing cell damage. Majority of the damage due to solar UV radiation is as a result of this little but intermittent and cumulative absorbed doses that turn out to affect the body in later stages of life (i.e. chronic effects). The chronic exposure gives rise to accelerated skin aging process, increases the risk of developing skin cancer, both melanoma and non-melanoma, eye cataracts, and pterygium [17] which are prominent in Central Nigeria especially within the age bracket of 50 years and above [18] report shows an increase in UV induced eye related diseases like cataract, pterygium and conjunctivitis in Central Nigeria.

The result clearly indicates that, people who allow direct penetration of UV radiation on their scalp are at high risk of developing chronic effects of UV exposure to radiation even without the acute effects. Although this result may vary in different individuals due to the way their heads are positioned. Apart from women who use artificial hairs on their heads and few covering their heads with head-ties and hats, a greater percentage normally leave their heads unprotected. The research has proven the necessity of always using head cover protection against high UV exposures which are normally concentrated at the upper extremities especially the scalp and eyes. Hats and shade 
should be used when carrying out different occupational and outdoor activities under intense solar irradiation.

\section{Conclusion}

The research made use of a chemical dosimeter fitted on an anatomical model of human (manikin) to gauge UV radiation on different body sites. UV radiation exposure on different human body sites varies with difference in body geometry. As a result of different behavioral patterns, levels of UV exposure awareness and exposure geometry, application of exposure limits is not practical as it is done in artificial UV radiation exposures, but seeking shade and limiting solar UV radiation exposures to as low as reasonably achievable is the effective approach.

\section{Acknowledgement}

The UV Polymer Polysulphone dosimeters were provided and supplied by Prof. Alfio Parisi, from University of Southern Queensland, Toowoomba, Australia.

\section{References}

[1] J. Badosa. UV Index: Measurement and Model Agreement Uncertainties and Limitations, A Ph.D Thesis, Universitat de Girona, Catalonia, ISBN 84-689-6849-8, 1-34, (2005).

[2] B.L Diffey. Solar Ultraviolet Radiation Effects on Biological Systems. Review in Physics in Medicine and Biology, 36(3), $299-328,(1991)$.

[3] K.L. Hatch \& U. Osterwalder. Garments as Solar Ultraviolet Radiation Screening Materials. Dermatologic Clinics, 24, 85, (2006).

[4] A.V. Parisi, D.J. Turnbull, \& J. Turner. Comparisons of the Biologically Spectra for Erythemal and Pre-vitamin D3 Synthesis, International Journal of Biometeorology, 53(1), 11-15, (2009).

[5] D.J. Turnbull, \& A.V. Parisi. Dosimeter for the Measurement of UV Exposures related to Melanoma Induction, Physics in Medicine and Biology, 55(13), 3767-3776, (2010).

[6] L.M. Meyer. Cataract Induced by UVR-B: Characterization and Genetic Modulation of Lens Sensitivity to Oxidative Stress, Department of Clinical Neuroscience St'Erik;s Eye Hospital, Karolinska Institutet, Stockholm, 1-26, (2008).
[7] D.P. Hader, H.D. Kumar, R.C. Smith, \& R.C. Worrest. Effects of Solar UV Radiation on aquatic ecosystem and Interactions with Climate Change, Journal of Photochemical and Photobiol Science, 6, 267-285, (2007).

[8] N.J. Downs, A.V. Parisi, S. Powell, C. Brennan, \& J. Turner. Extensions in Pen Ink Dosimetry: Ultraviolet Calibration Applications for Primary and Secondary Schools. Teaching Science: The Journal of the Australian Science Teachers Association, 56, 51-56, (2010).

[9] N.J. Downs, J. Turner, A.V. Parisi, \& J. Spence. Pen Ink as an Ultraviolet Dosimeter, Teaching science Journal, 54 (4), 41-44, (2008).

[10] C.S. Cockell. Biological Effects of High Ultraviolet Radiation on early Earth - a Theoretical Evaluation. Journal of Theoretical Biology, 193, 717-729, (1998).

[11] I. Chiemeka. Estimation of Solar Radiation at Uturu, Nigeria, International Journal of Physical Sciences, 3(5), 126-130, (2008).

[12] A. Offiong. Assessing the Economic and Environmental Prospects of stand-by Solar Powered Systems in Nigeria, Journal of Applied Science and Environmental Management, 7(1), 37-42, (2003).

[13] World Bank (2012). Land area (sq. km) in Nigeria, Retrieved September 8, 2013, from $\mathrm{http} / /$ www.tradingecomics.com/nigeria/land-area-sq-km-wb -data.html

[14] GENI.Available: http:/geni.org/globalenergy/library/renewable-energy-resou rces/index.shtml.

[15] A.V. Parisi \& D.J. Turnbull. Solar UV dosimetry. In: UV Radiation and its Effects: an Update 2006, Dunedin, New Zealand, (2006).

[16] D.J. Turnbull \& A.V. Parisi. Seasonal variation of facial UV Exposures in the Shade. Household and Personal Care Today (4-su). 14-17, (2011).

[17] ICNIRP (2007). Protecting Workers from Ultraviolet Radiation (ISBN 978-3-934994-07-2) retrieved from http:www.who.int/uv/publications/protecting_workers_uv_p ub.pdf.

[18] Community Based Management. Statistical Return Data of Eye patients Consulted from NKST Eye Care Program, Mkar, Gboko, Project 364, (2011). 